\title{
EN TORNO AL TIPO MELPÓMENE FARNESIO EN ESCULTURAS ROMANAS DE HISPANIA
}

\author{
Luis BAENA DEL ALCÁZAR \\ Universidad de Málaga
}

\section{Resumen}

En esta comunicación se aborda la problemática del tipo femenino vestido conocido como Melpómene Farnesio, el cual fue creado durante la época helenística y se difundió en el mundo romano para las representaciones de divinidades, singularmente musas y personificaciones. Se aborda también, en este estudio, el caso de otras figuraciones de divinidades de corte helenístico, que presentan problemas de diversa índole en su indumentaria.

\begin{abstract}
In this communication we talke about the subject of dressed feminine type known as Melpomene Farnese, which was born during hellenistic age and was diffused all over romans world for representing divinities, specially muses and personifications. We also talk, in this study, about the question of others hellenistic divinity figurations, which are difficult to define its clothing.
\end{abstract}

Cuando abordé el estudio tipológico de las esculturas femeninas vestidas de Hispania', entre otras muchas esculturas, me llamó poderosamente la atención una figura escultórica cuyo prototipo presenta complejos problemas de difícil resolución y cuya investigación ha constituido un verdadero campo de batalla por todo aquel investigador que se ha enfrentado a su estudio.

La escultura en cuestión es una figura femenina vestida, de unos $53 \mathrm{cms}$. de alto, halladaen las Ilamadas "Termas inferiores" procedente de laimportante villa de Els Munts",

'L. BAENA DEL ALCÁZAR, (1998), (en prensa). Conunicación a la III Reunión sobre Escultura romana en Hispania celebrada en Córdoba en 1997.

${ }^{2}$ M. BERGES, (1969-1970), p.147, lám. III, la identifica como una divinidad de la tierra. 
conservada en la actualidad en el Museo Nacional de Tarragona. (FIG. 1,1 y LÁM. I,1) De ella se ocupó A. Balil que la clasificó acertadamente como una copia tardía, de la segunda mitad del siglo II d.C., de un tipo concreto de musa ${ }^{3}$, que se conoce en la literatura científica como Melpómene Farnesio, por la copia de la estatua que perteneció a esta familia, que se guarda hoy en el Museo Nazionale de Nápoles ${ }^{4}$.(LÁM. II,1)
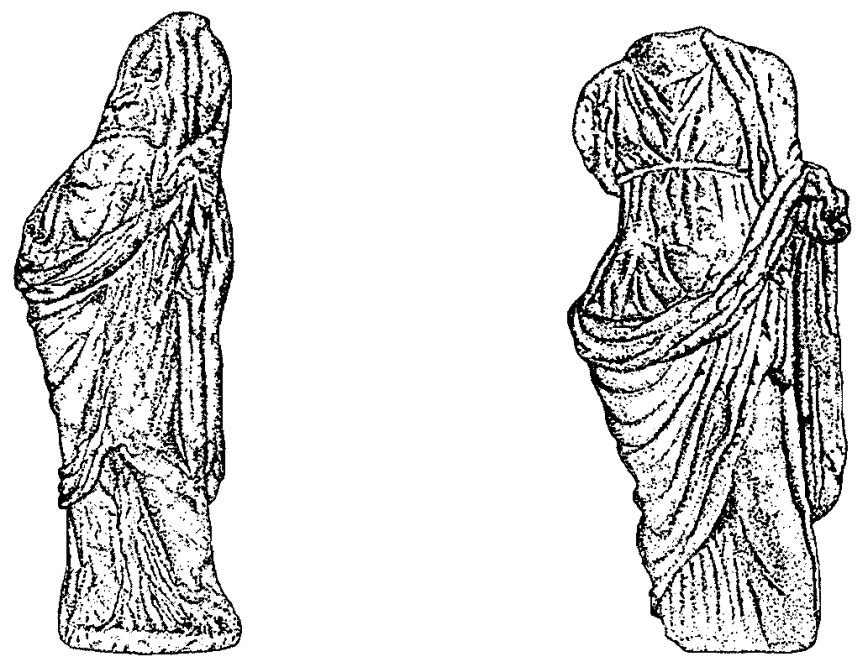

TIPO MUSA MELPOMENE FARNESIO.

1. Calahorra.

2. Altafula.

Dibujo: J.M. Moyano Carballo

La figura, aunque mutilada - carece de cabeza, brazo derecho, parte inferior de las piernas y el atributo que portaba en la mano izquierda -permite una perfecta identificación con los elementos conservados. Viste un fino chitón, dato éste a tener en cuenta para establecer su filiación, que moldea la figura permitiendo admirar las curvas femeninas. Son patentes sobre todo en la cadera derecha, elevada con respecto a la contraria, por sostener la pierna de este lado el peso del cuerpo, mientras que la izquierda se adelanta y se flexiona. La túnica, con mangas, se ciñe con un fino cordón bajo el pecho, el cual queda, además, marcado por los pliegues abiertos que bajan del escote. Se cubre con un himatión.

\footnotetext{
${ }^{3}$ A. BALIL, (1983 a), pp. 36-38, n 140, lám.XVII,3; ID., (1983), pp. 263-265, n 140;

${ }^{4}$ El tipo, en esencia, recrea el tipo de la Themis de Ramnunte en la colocación de los paños y como tal la incluimos en el grupo perteneciente a este tipo de figuras en el trabajo mencionado en la nota 1, aunque es evidente que, por la estructura corporal, la pieza encaja perfectamente entre las copias del prototipo de Nápoles. Sobre esta escultura en particular, cfr. A. RUESCH, (s.a.), p. 161, nº 515.
} 
Uno de sus extremos cae por el hombro izquierdo cuya continuación, tras pasar terciado por la espalda, ciñe la cadera derecha con un grueso haz de pliegues que, formando una amplia comba en la parte delantera, se recoge con el brazo izquierdo cayendo luego en un haz de pliegues verticales. Es posible que el himatión velase la cabeza de la figura, como ocurre en otras copias, la cual por lo poco que queda del cuello, la inclinaría levemente hacia la derecha. La mano izquierda sostiene el extremo de un objeto en el que se reconoce la parte inferior de una cornucopia, elemento que no es propio de una musa pero que en numerosas esculturas, por gusto del copista, se incorpora.

Toda la composición - estructura corporal y disposición de los ropajes - la emparenta, como se ha apuntado, con la escultura que antaño adquiriera la familia Farnesio. Esta pieza, pese a no ser la mejor copia, es cabeza de serie de un pequeño grupo de figuras que poseen estilísticamente características similares ${ }^{5}$. El tipo escultórico nos lleva a retomar el problema del modelo original, al tiempo que de manera subsidiaria queda planteado el tema relativo a su presencia en una rica villa de la Tarraconense, referido, fundamentalmente, a la pervivencia del tipo iconográfico, a su funcionalidad y a su significado.

Buscar el prototipo de esta figura es ardua tarea, aunque sin dificultad se reconoce su presencia en dos relieves, bien conocidos, conservados en el Museo Británico. Ambos poseen una cronología que se sitúa, aproximadamente, en los comedios del siglo II a.C.. El primer relieve es el de una basa, de $82 \mathrm{cms}$. de alto, con un grupo de nueve figuras que se reconocen como musas ${ }^{6}$. Una de ellas, la que apoya la mano sobre una gran cítara, posee un ritmo corporal y una disposición de los vestidos similar a la figura en estudio. (LÁM. IV,1)Las actitudes de ésta y de las otras ocho figuras tienen su correspondencia más o menos exacta con la famosa lastra marmórea hallada en Boville, en la que se representa la llamada "Apoteosis de Homero" firmada por Arquelao de Priene ${ }^{7}$. (LÁM. III,1) Haciendo abstracción de la problemá-

\footnotetext{
${ }^{5}$ El elenco de piezas fue realizado por D. PINKWART, (1965), pp. 208-209, que reunió once esculturas en bulto redondo y dos relieves. Esta lista fue repetida por L. DE LACHENAL, (1979), pp.119-120 al estudiar la excelente copia del Museo Nazionale Romano (LÁM. I,2) la cual fue reconocida como musa por G. BATTAGLIA, (1934) pp. 7 ss., y por A. BALIL, loc.cit., añadiendo la pieza de Els Munts. A esas doce piezas han de añadirse las dos que se estudian en nuestro texto, ver infra, procedentes de Villaralbo y de Calahorra, con su correspondiente bibliografía. A todas estas ha de sumarse la Melpómene que apareció en el teatro de Ferento: P. PENSABENE, (1989), pp. 69-71, lám.60, y algunos fragmentos estatuarios hallados en Cos: L. LAURENZI, (1955-1956), pp.95 ss.

${ }^{6}$ D. PINKWART, (1967), pp.89 ss.

${ }^{7}$ Entre otros: C. WATZINGER, (1903), pp. 1 ss.; J. SIEVEKING, (1917), pp. 74 ss.; M. SCHEDE, (1920), pp. 69 ss.; W. KLEIN, (1921), pp.119 ss.; G. LIPPOLD, (1950), p.703; M. BIEBER, (1955), p.127 s.; L. GUERRINI, (1958), p.543; D. PINKWART, (1965), pp. 19-90; P. MORENO, (1994), p.574.
} 
tica que posee esta obra y de la identificación de determinados personajes ${ }^{8}$, es evidente la coincidencia de figuras, entre las cuales, en el segundo registro, puede reconocerse a Melpómene ${ }^{9}$ (LÁM. III,2) en aparente conversación con Talia, musa de la Comedia, flanqueadas por sendas divinidades sentadas en las que se quiere reconocer a Clío en el extremo izquierdo y, en el derecho, a Euterpe.

El problema verdadero comienza con la atribución de grupo original, del que estos relieves serían copia, a Filisco de Rodas ${ }^{10}$, escultor cuya actividad, discutida, se fecha en los primeros treinta años del siglo II a.C.". De este artista serían las esculturas que decoraban el interior del templo de Apolo in circo, edificado en Roma a finales de la República y reedificado en tiempos de Augusto por $C$. Sosius, según nos transmite Plinio $^{12}$. Precisamente en la cella de este templo se encontró una cabecita femenina de mármol griego, hoy en el Museo Capitolino, que se correspondería, según el documentado trabajo de La Rocca ${ }^{13}$, en la musa que lleva la cítara pequeña y que permitiría confirmar esta atribución por afinidad con otras cabezas de divinidades similares ${ }^{14}$. La ejecución de estas figuras estaría fechada hacia el año 179, puesto que estas esculturas se copian en terracota en el frontón del templo de Luni, que es algo posterior ${ }^{15}$.

Sin embargo, existe un problema de difícil solución en relación con la atribución del grupo de musas a Filisco por la existencia de una obra firmada por otro Filisco,

\footnotetext{
${ }^{8}$ Sobre la identificación de los rostros de las figuras alegóricas de Oikumene y Cronos, situadas tras Homero, con monarcas helenísticos: L. LAURENZI, (1965), p.123; D. PINKWART, (1965), lám. 10; E. LA ROCCA, (1984), p. 638, nota 45; P. MORENO (1994), p.574, nota 927; J.ONIANS, (1996), pp.148-151. Específicamente sobre la mentalidad erudita en las cortes helenísticas que hacen posible la creación de obras como esta: J. J. POLLITT, (1989), pp.41ss.
}

${ }^{9}$ C. WATZINGER, (1903), pp. 9-10, nº 7, fig. 5; D. PINKWART, (1965), pp.143-145; P. MORENO, (1994), p.578.

${ }^{10}$ Atribución que hizo W. AMELUNG, (1895), aceptada durante muchos años por la inmensa mayoría de los investigadores. Sobre la figura controvertida de Filisco de Rodas: R. HORN, (1931), pp.67 ss; G. LIPPOLD, (1937), col.2388 ss; W. KROLL, (1938), cols. 2978 ss. L. LAURENZI, (1955-1956), pp.122-123; M.BIEBER, (1955), pp.I27 ss.; D.PINKWART, (1965), pp. 91-169; L. LAURENZI, (1965 b), pp. 762-763.

${ }^{11}$ L. GUERRINI, (1965), p.122; E. LA ROCCA, (1984), p.641.

${ }^{12}$ PLINIO, N.H., XXXVI, 34. “...Apollo Philici Rodii in delubro suo, item Latona et Diana et Musae noven et alter Apollo nudus". Versión de J. ANDRÉ - R. BLOCH - A. ROUVERT, (1981) p. 60 y pp 159-160.

${ }^{13}$ E. LA ROCCA, (1984), pp. 629 ss.

${ }^{14}$ IBID., pp. 634-635. D. PINKWARD, (1965), p.101; P. MORENO, (1994), I, figs.529-530.

${ }^{15}$ D. PINKWART, (1965), p. 107 ss. piensa que las esculturas de Filisco en el templo de Apolo in circo habría que fecharlas entre 160 y 150, pero E. LA ROCCA. (1984), p. 635, nota 31, opina que, pese haber sido aceptada esta cronología por otros investigadores, habría que rebajarla algunos años en razón de las figuras del templo de Luni, colonia fundada en el año 177 a.C. De la misma opinión es P. MORENO, (1994), p.409. La construcción del templo de Apolo se situaría en el año 179 por dedicación del censor de ese año M. Aemilius Lepidus. 
hijo de Policarmo, de Rodas, fechada en el siglo I a. C. ya avanzado ${ }^{16}$. Se trata de la estatua, de corte clasicista, de la sacerdotisa Are en el santuario de Artemis Polos en $\operatorname{Tasos}^{17}$. De querer identificar a este escultor con el Filisco de las estatuas del templo de Apolo Sosiano, que vivió, como se ha dicho, en la primera mitad del siglo II, las musas no podrían ser obra suya por dificultades estilísticas. Aunque esta circunstancia echaría por tierra toda la teoría expuesta anteriormente, de tal manera que prestigiosos investigadores como M. Bieber ${ }^{18}$ y A. Adriani ${ }^{19}$ aconsejan abandonar la idea de atribución del grupo de musas al Filisco del siglo II. Laurenzi, sin embargo, propone la existencia de dos personajes con el mismo nombre. El escultor que firma en Tasos sería el tataranieto del Filisco de las musas ${ }^{20}$. Con esta hipótesis de compromiso, si se acepta, quedaría resuelto el problema.

En conclusión podemos decir, siguiendo a P. Moreno, que Filisco de Rodas es autor de dos grupos de musas. Uno, oriental, realizado en Rodas es el que se copia en el relieve de Arquelao de Priene. Una segunda versión, réplica de la anterior pero no exactamente igual, sería la efectuada para el templo de Apolo en Roma, donde las musas ocupaban nichos en los laterales de la cella ${ }^{21}$. Con respecto a la cabeza hallada en este lugar, se restituye la figura mediante una musa de Mileto, hoy en Estambul y otra de Munich 22 .

Estos grupos de musas fueron muy admirados en época romana, lo que se prueba por el gran número de copias que han llegado hasta nosotros. Su función como estatuas de culto, salvo algún caso aislado, como tal vez éste de Apolo sosiano o el grupo que también se encontraba en Roma en el templo de Hércules y las Musas ${ }^{23}$, lo más

${ }^{16} I . G .$, XII, Suppl., 383.

${ }^{17}$ G. MENDEL, (1912), (Ed.anast. 1966), I, pp.345 ss., n 136 y III, pp.557 ss, no 1352; M. SCHEDE, (1920), 35 ss. y 65 ss.; L. LAURENZI, (1965 b), p.762; ID., (1965 a), p.123.

${ }^{18}$ M. BIEBER, (1955), p.127. El propio G. MENDEL, (1912), n 1352, ya dudaba de tal atribución.

${ }^{19}$ A. ADRIANI, (1931), pp.179 ss.; También es de esta opinión D. MUSTILLI, (1938), p.79.

${ }^{20}$ L. LAURENZI, (1965 a), p. 123.

${ }^{21}$ P. MORENO, (1994), I, p.409, notas 720 y 721; E. LA ROCCA, (1984), p.642.

${ }^{22}$ Un grupo de musas fue hallado en las termas de Faustina en Mileto, recinto excavado por TH. Wiegand, en 1905, actualmente conservadas en el Museo de Estambul: G. MENDEL, (1912), I, pp.316 ss., n'os.114-129. Sobre la restitución comentada: P. MORENO, (1994), p.410, figs.529-530. Elenco de réplicas en D. PINKWART, (1965), pp.210-211.

${ }^{23}$ Templo construido en Roma en el año 187 a. C. para albergar las Musas de bronce que el cónsul del $189 \mathrm{M}$. Fulvius Nobilior trajo de Ambracia, entre otros despojos, de la colección de arte de Pirro. PLINIO, N.H., 35, 66. Sobre las musas de Ambracia: D. PINKWART, (1967), p.92, nota 9; B.S. RIDGWAY, (1990), pp.246 ss. y fig.30. M. T. MARABINI MOEVS, (1981), pp.1-58, con noticias y reproducciones de estas musas según las monedas de Pomponio Musa y las que aparecen en la cerámica aretina, pp.8-20. 
frecuente es encontrarlas como ornamento de lugares de espectáculo ${ }^{24}$, en termas ${ }^{25}$, en contextos funerarios ${ }^{26} \mathrm{y}$, sobre todo, en villae más o menos lujosas de donde proceden los conjuntos más famosos ${ }^{27}$.

Es precisamente en el ámbito privado donde hallamos en Hispania las figuras de musas. La que estudiamos, de la villa de Els Munts, pudo tener un sentido ambivalente entre lo decorativo o entre la posible intención intelectual de su propietario. Parece abonar la primera hipótesis el hallazgo en el mismo lugar de una estatua de Hygeia ${ }^{28}$ de tamaño similar que, con toda probabilidad, estuvieron destinadas a ser colocadas en nichos u hornacinas. Con ellas se relaciona, además, la cabeza de Tyché - Fortuna, diademada y torreada que se halló con las anteriores ${ }^{29}$.

Pero volviendo a retomar el análisis de las esculturas del tipo Melpómene Farnesio, y una vez más en relación con su aparición en ámbitos privados ha de traerse a colación una pequeña figura, tan solo alcanza los quince centímetros, procedente de Villaralbo (Zamora) ${ }^{30}$, conservada en una colección particular, que ha de considerarse excepción al significado decorativo pues en este caso, dadas las pequeñas dimensiones de la pieza, ha de adscribirse dentro de la casa a un entorno religioso, tal vez como perteneciente a un larario ${ }^{31} \mathrm{o}$, al menos, a un culto doméstico ${ }^{32}$.

${ }^{24}$ Sirva como ejemplo singular el grupo de musas colocadas la frons scaena del teatro de Ferento: P. PENSABENE, (1989), pp.69 ss..

${ }^{25}$ Las ya mencionadas termas de Mileto o las termas de Agnano de donde procede el grupo escultórico de Francfort. Vid. infra. Sobre la decoración de termas con musas: B.S RIDGWAY, (1990) p.255, nota 11.También en termas privadas como la figura que aquí se estudia.

${ }^{26}$ I. LINFERT - REICH, (1971), pp.14-23.

${ }^{27}$ Por las fuentes conocemos el gusto de romanos ilustrados de poseer esculturas de musas en sus domus y villae de recreo, a veces en lugares ad hoc como bibliotecas. PLINIO, N.H., 36, 33 (en la colección de Asinio Polion); también en jardines: CICERON, Ad fam., VII, 23, 1. Sobre este tema G.BECATTI, (1951), p. 93. De la llamada "Villa di Cassio", al sur de Tívoli, son el grupo de musas, halladas en el año 1774, que hoy se exponen en la sala del mismo nombre de los Museos Vaticanos. Sobre la villa y sus hallazgos: C.PIETRANGELI, (1949-1951), pp.157-181. El estudio pormenorizado de las esculturas de corte netamente clasicista: H. VON STEUBEN en W. HELBIG, (1963), I, ${ }^{\circ}{ }^{\circ} .60,63,65,68,77,80,82,84,128$, pp.48 ss. Véase infra sobre los descubrimientos de Villa Adriana y de Agnano. Sobre las representaciones de musas en todo tipo de objetos en el mundo greco-romano, incluyendo en el catálogo las piezas principales aquí estudiadas y toda la bibliografía general anterior, véase A. QUEYREL (1992), pp.657 ss.; L.FAEDO, (1994 a), pp.991 ss.; J. LANCHA, (1994), pp.1013 ss.

${ }^{28}$ A. BALIL, (1986 a), nº 73, pp. 35-36, lám.XIV, 1-2; ID., (1986 b), p.214,

${ }^{29}$ ID., (1986 a), pp.37-38, $\mathrm{n}^{\circ} 175$.

${ }^{30}$ ID., (1988), p.234, n 197, lám.IX.

${ }^{31}$ Sobre la presencia de divinidades en lararios: P. RODRÍGUEZ OLIVA, (1994), pp. 24 27, con la bibliografía correspondiente. A este respecto recuérdese el larario pintado de Bilbilis con figura de Fortuna, y los restos de otro en Carthago Nova, con tres arae, y las figurillas de bronce, entre ellas Fortuna, en la villa de Villauba. 
Una tercera escultura variante del tipo que venimos tratando es la de Calahorra, en la Rioja, que, como las citadas es de tamaño menor del natural ${ }^{33}$. El ritmo corporal de esta figura, sosteniendo el peso con la pierna derecha y la izquierda, retrasada, destacando bajo los pliegues del vestido es similar a las otras de la serie, variando, no obstante, en la colocación de los pliegues bajo el pecho. (FIG. 1,1)

El tipo de la musa Melpómene Farnesio si no demasiado abundante en esculturas de bulto redondo, como ya se ha visto, si tiene cabida en otra clase de representaciones que demuestran la vitalidad del modelo original. Es el caso de algunos tipos de Victorias que toman prestada la disposición de la vestimenta, como aquéllas de Samotracia o, repitiendo el esquema, en esculturas más tardías, como sucede en la Isis de Delos. Interesantes son, igualmente, por permitir una datación bastante precisa, hacia el $150 \mathrm{a}$. C., las tetradracmas acuñadas por Mitrídates IV Filopator, rey del Ponto, en las que aparecen representadas en el reverso él mismo y su hermana y esposa Laodicea V Filadelfia como Zeus y Hera respectivamente.(LÁM. II,2) Laodicea aparece ya sola en un ejemplar de la Colección Waddington ${ }^{34}$. Finalmente, el modelo escultórico se traspone a las matrices de las cerámicas aretinas en compañía de otras musas ${ }^{35}$. En este caso Melpómene no lleva su atributo habitual, la máscara, desde las reelaboraciones alejandrinas, sino una cítara pequeña, como aparece en el relieve de Arquelao de Priene.

Si consideramos el fenómeno de la pervivencia de los tipos de musas de corte helenístico y su difusión en la Península Ibérica, las tres figuras estudiadas no son, ni muchísimo menos, casos únicos o aislados en localidades muy distantes entre sí. Contamos, por el contrario, con otros ejemplares de musas de singular importancia repartidas a lo largo de la costa mediterránea a las que me parece pertinente referirme porque su iconografía está en estrecha relación con los ejemplares que hemos analizado. No es, evidentemente, en lo formal puesto que son esculturas distintas, pero sí en la génesis de las mismas que, como la Melpómene Farnesio, tienen su punto de partida en el relieve de Arquelao de Priene y en la Basa de Halicarnaso.

En efecto, de Cartagena, en su Museo Arqueológico Municipal y labrada en mármol pario, es la interesante escultura que representa a Polimnia ${ }^{36}$. (LÁM. V,1) Es una

\footnotetext{
${ }^{32}$ Su editor señalaba, creemos que muy acertadamente, la posibilidad de adscripción al ciclo estacional o bien en relación con Abundantia en su aspecto agrario. A. BALIL, (1988), loc. cit.

${ }_{33}^{3}$ ID., (1988), p. 229, n 192, lám. VII.

${ }^{34}$ Para la pervivencia del tipo en otros materiales no estatuarios: L. DE LACHENAL, (1979), p.121; A. BALIL, (1983 b), p.264. D. PINKWART, (1965), lám. 10 a-b; G. KLEINER, (1942), p. 214, lám. 40, a-c. ${ }^{35}$ G. FIORELLI, (1884), p. 377, lám.8; O.BIE en W. H. ROSCHER, (1894), col.3267, fig. 6.

${ }^{36}$ A. BALIL, (1988) p. 238, n 202; J. M. NOGUERA CELDRÁN, (1991), pp. 55-56, nº 8, lám.11, 1-2.
} 
figura que, adelantando el cuerpo se apoya, según las versiones, en una roca, en una pilastra o, como sucede en este caso, en un tronco. Se cubre el cuerpo con un amplio manto que se adapta a la figura y que envuelve también los brazos, uno, en posición horizontal sosteniendo el cuerpo sobre el soporte y el otro, dispuesto verticalmente, permitiendo a la cabeza, que mira al frente, descanse sobre él. Esta original postura confiere a la escultura un aspecto de introversión o de meditación. Desgraciadamente de estos últimos extremos carece, por rotura, la copia de Carthago Nova, pero si lo conservan otros ejemplares. Es un tipo de musa que por su singularidad hizo fortuna en época helenística y romana probado por la gran cantidad de copias existentes. Aparece claramente en el tercer registro de la llamada "Apoteosis de Homero"37, (Lám. III,2) casi inmediatamente debajo de su hermana Melpómene, e igualmente vuelve a aparecer en la Basa de Halicarnaso ${ }^{38}$. (LÁM. IV, 2) Sea el prototipo creado por Filisco o por otro escultor lo cierto es que varios investigadores atribuyen a su autor una gran originalidad y una enorme sensibilidad para la composición, añadiendo el elemento virtusista del himatión que, transparente, deja traslucir la tela más gruesa del chitón ${ }^{39}$.

Posiblemente el ejemplar más completo y bello es el conservado en el Museo Nuovo Capitolino ${ }^{40}$, que parece seguir fielmente el perfil del relieve de Arquelao. (LÁM. V,2) A esta pieza, que puede considerarse cabeza de serie, siguen otras veintiuna de distintos tamaños realizadas en bulto redondo según la recopilación que hiciera Pinkwart ${ }^{41}$, sin contar los relieves, las terracotas y las representaciones en otros objetos ${ }^{42}$.

Además, a partir de la creación de los sarcófagos con musas y de filósofos se la representa de perfil con muchísima frecuencia en uno de los extremos del friso frontal de la caja mortuoria ${ }^{43}$. Así sucede, por ilustrar algunos casos hispanos, en el sarcófago del Museo Etnográfico de Belem (Portugal) en donde se la reconoce todavía, pese a la diferencia de talla y modelado, en su pose habitual, es decir, envuelta en su manto y

${ }^{37}$ D. PINKWART, (1965), pp.187 ss., lám. 1.

${ }^{38}$ D. PINKWART, (1967), pp. 89 ss., fig.3, lám.53, a.

${ }^{39}$ P. MORENO, (1994), pp. 410-411, fig. 527.

${ }^{40}$ D. MUSTILLI, (1939), pp.78 s., nº 24, lám.46.

${ }^{41}$ D. PINKWART, (1965) pp.187 ss., entre ellas la del Museo del Prado que perteneció antiguamente a Cristina de Suecia y a L. Odescalchi, comprada por Felipe V de España en 1724. A. BLANCO FREIJEIRO, (1957), pp.35-36, nº 32 E, lám.XVII.

${ }^{42}$ D. PINKWART, (1965), pp.197-198, ns. 20 a 24.

${ }^{43}$ C. PANELLA, (1966-1967), pp. 29 ss.; L. PADUANO FAEDO, (1981), pp.65 ss.; L. FAEDO, (1994 b), pp. 1030 ss. 
apoyada en un fino pilar ${ }^{44}$. También puede reconocerse aquí la figura de Melpómene, aunque ya no recuerda, ni de lejos, las poses helenísticas. Sin embargo, las reminiscencias helenísticas si están presentes en la pareja, entre las demás, de las dos musas que tratamos en el sarcófago que se descubrió en la catedral de Tarragona y hoy guarda su Museo Diocesano ${ }^{45}$. Aquí Melpómene incluso conserva el kolpos bajo el pecho y adelanta la pierna izquierda y, una vez más, Polimnia en uno de los extremos se encuentra con su aspecto tradicional. La musas de este sarcófago y el de otros muchos llevan sobre la cabeza una pluma, que se interpreta tras los trabajos de F. Cumont ${ }^{46}$ como el poder creador de las musas y su victoria sobre las sirenas y que alude al triunfo de la inteligencia sobre las tinieblas del espíritu representadas por aquellos genios del mundo de los muertos $^{47}$, simbología que se aplica a la presencia de estas divinidades en los sarcófagos. Todavía más evidentes son los resabios clásicos en el ejemplar de la catedral de Mur$\mathrm{cia}^{48}$, en donde Melpómene conserva en lo esencial la estructura corporal comentada, aunque aquí el copista ha transformado la disposición de los ropajes. En el extremo, como siempre, Polimnia, una vez más arropada en el manto y cruzando las piernas. Finalmente en el Museu do Carmo de Lisboa reaparecen una vez más Melpómene con kolpos bajo el pecho y máscara trágica y Polimnia que en este caso se representa de frente y con las piernas cruzadas por delante del cuerpo ${ }^{49}$. Todos estos sarcófagos se fechan en el siglo III, que atestiguan la pervivencia de los tipos creados cinco siglos antes, aunque su significación varía totalmente, conservando, eso sí, la atribución simbólica a la inteligencia y a la sabiduría.

Retornando al análisis de las figuras de bulto redondo debemos referirnos a otra musa que también está vinculada a los prototipos que se encuentran en la Basa de Halicarnaso ${ }^{50}$ y por ello emparentada, igualmente, con los grupos de musas creadas por el arte de Filisco. Nos referimos a una escultura representando a Urania, sedente, con la esfera a sus pies, detalle este del que carecen otras copias, que se halló en Churriana (Málaga) en lo que se

${ }^{44}$ A. GARCÍA Y BELLIDO, (1949), p.241, nº.260, lám.197; M. WEGNER, (1966), p.12 ss.; V. DE SOUZA, (1990), pp.49-50, $\mathrm{n}^{\circ} 138$.

${ }^{45}$ A. GARCÍA Y BELLIDO, (1949), pp.228-230, no 254, lám.188; M. WEGNER, (1966), pp.85 ss.

${ }^{46}$ F. CUMONT, (1942), pp. 23 y 235.

${ }^{47}$ A. GARCÍA Y BELLIDO, (1949), p.229.

${ }^{48}$ ID., (1949), pp.230-233, n 255, 1áms.189-190; M. WEGNER, (1966), pp.28 ss.; J. M. NOGUERA CELDRÁN, (1992-1993), pp.293-311, con un estudio sobre el significado simbólico y bibliografía actualizada sobre el tema.

${ }^{49}$ A. GARCÍA Y BELLIDO, (1949), pp.233-234, no 256, lams.191-193; M. WEGNER, (1966), pp.22 ss.; V. DE SOUZA, (1990), p. 48, n 136.

${ }^{50}$ D. PINKWART, (1967), p. 91, fig. 42, reconoce la figura en cuestión (Urania) en una de las figuras de la Basa. 
supone sería una villa, hoy en el cementerio de Bilbao sirviendo de ornamentación de un mausoleo.(LÁM. VI,1) Es pieza conocida de antiguo pues, publicada por Rodríguez de Berlanga ${ }^{51}$, pronto fue recogida por Lippold ${ }^{52}$ identificándola con la escultura similar del Liebieghaus Museum de Francfort ${ }^{53}$, la cual procedía de las termas de Agnano, localidad cercana a Puteoli. Esta pieza, que da nombre a la serie, encabeza una lista de copias, establecida por Pinkwart ${ }^{54}$. Esta investigadora sostiene la hipótesis de asociar o emparentar este prototipo con el arte de Filisco, opinión que se ve contrarrestada por un grupo de investigadores que, aun admitiendo un origen rodio o microasiático para el modelo original, opinan que la escultura de Agnano se inspira en modelos diferentes, muy posiblemente imitando la composición de la musa sedente que aparece en el Altar de Atenea en Priene, fechada hacia el año 230 a.C. ${ }^{55}$. Es interesante indicar el parentesco estilístico que se advierte con otras creaciones del primer helenismo como la Tyché de Antioquía sobre el Orontes, obra de Eutiquides ${ }^{56}$, especialmente en el cruce de las piernas y los consiguientes pliegues que provocan en el manto. Esta búsqueda de los valores tridimensionales de la escultura mediante la posición adelantada del tronco y la inclinación de la cabeza sostenida por uno de los brazos nos indican una clara influencia lisipea, como no podía ser menos en uno de sus discípulos más aventajados ${ }^{57}$.

En relación directa con la musa Urania, de la antigua colección Loring, son dos interesantes cabezas femeninas de gran calidad técnica que, por haber aparecido juntas en tiempo y contexto arqueológico, las hemos considerado también como musas ${ }^{58}$. No obstante, al haberse conservado tan solo las cabezas con peinados genéricos que en la escultura antigua fueron comunes no sólo a las musas, sino también a Venus o,

${ }^{51}$ M. RODRÍGUEZ DE BERLANGA, (1903), p.97, nº XVII, lám. XVII.

${ }^{52}$ G. LIPPOLD, (1918), p.65, nota 1. Estudiada con posterioridad por A. GARCÍA Y BELLIDO, (1949), p.170, n ㅇ 186, lám.140; A. BALIL, (1960), pp.238 ss; ID., (1975), pp.32-35; ID., (1978), pp.12-15, nº lám. V.

${ }^{53}$ Sobre las musas de Francfort: P. C. BOL, (1983), pp.126 ss., n's.36-46. Una visión de conjunto de estas musas y en particular de Urania: B. S. RIDGWAY, (1990), pp.259 ss., lám. 130 a-c.

${ }^{54}$ D. PINKWART, (1967), pp.139 ss. y 205 ss. Recopila 13 ejemplares en bulto redondo, 2 relieves y 2 terracotas. Entre las mejores copias destacan el torso Afyon Karahusar , n⿳o 3, láms. 7 a-b, 8 a-b; (LÁM. V1.2) y el torso Aydin, $n^{\circ} 5$, lám. $8 \mathrm{c}$-d.

${ }^{55}$ A este respecto véanse las opiniones de B. S. RIDGWAY, (1990), pp. 252 y 260 ss.; P. MORENO, (1994), II, p. 677. Discusión sobre el ropaje de Urania: J. C. CARTER, pp.754-755.

${ }^{56}$ PAUSANIAS, VII, 2, 6

${ }^{57}$ G. LIPPOLD, (1918), pp.64 ss.; P. MORENO, (1994), I, pp.158-161, con bibliografía sobre esta creación de Eutiquides. De la zona de Antequera procede un bronce representando a Antioquía sobre el Orontes, que conserva numerosos puntos con las otras copias conservadas: A. GARCIA Y BELLIDO, (1949), pp. 171172, n 187 , lám.141.

${ }^{38}$ L. BAENA DEL ALCÁZAR, (1984), pp.49-57, nº. 6 y 7, láms.7-9. 
incluso a Apolo, no es fácil individualizar y otorgar nombres con certeza. En una de ellas de bellas y finas facciones con un complicado tocado en forma de lazo, el krobylos, y el resto del pelo de bucles ondulados recogido en la nuca mediante un moño, composición ésta harto frecuente, quisimos ver una imagen de la llamada Caliope del Museo del Prado que, como se ha indicado, procede de Villa Adriana ${ }^{59}$. Una cabecita similar, que una visión superficial haría pensar en un mismo taller por su gran similitud, es la hallada en el siglo XIX en la "Cantera del Puerto" de Tarragona. La confrontación entre ambas indica un mismo modelo, aunque las facciones de la escultura tarraconense son más carnosas que las de la cabeza de Churriana. Su última editora la identifica con Venus ${ }^{60}$, lo cual no es de extrañar por el peinado característico, aunque otros no han dudado en identificarla como Diana ${ }^{61}$. Abonando la idea de musa, propuesta por nosotros, véase una cabecita muy similar en el Museo de Estambul procedente de las termas de Faustina en Mileto ${ }^{62}$.

La última cabeza procedente de Churriana, hermana de la anterior y de Urania, hemos de considerarla también como una musa por los paralelismos que ya tuvimos ocasión de desarrollar en otro lugar, emparentándola con el rostro de la Polimnia del Prado, que es copia a su vez de la Clío del Vaticano ${ }^{63}$.

Siha quedadopuestode manifiesto la afinidad de los modelos de Melpómeney Polimnia con alguno de los grupos de Filisco y su indudable filiación con los relieves del Museo Británico, parece que también es admisible la estrecha relación de la escultura de Urania Loring - Francfort, con la salvedad de la respetable opinión de Pinkwart, con otras dos figuras de musa, una hallada en Cartagena ${ }^{64}$ (LÁM. VII,1) y otra en Sagunto ${ }^{65}$ (LÁM. VII,2) que sus editores han identificado como copias de la Melpómene del Liebieghaus Museum de Francfort ${ }^{66}$ que, como la Urania, procede de las termas de Agnano.

Se representa esta musa de pie sosteniendo el cuerpo con la pierna derecha - en algunas versiones con la izquierda - mientras que con la contraria, levantada, se

\footnotetext{
${ }^{59}$ A. BLANCO FREIJEIRO, (1957), p.41, nº 40 E, láms. 27 y 31. Sobre las musas del Museo del Prado: K. M. TURR, (1971).

${ }^{60}$ E. M. KOPPEL, (1985), p.71, no 93, lám.34, 1-4.

${ }^{61}$ A. GARCÍA Y BELLIDO, (1949), p. 144, nº 152, lám. 114.

${ }^{62}$ G. MENDEL, (1912), I, p. 328, nº 121.

${ }^{63}$ L. BAENA DEL ALCÁZAR, (1984), p. 57.

${ }^{64}$ A. BALIL, (1980), pp. 6-7, n 36; J. M. NOGUERA, (1991), pp. 56-58, nº 9, láms. 12 y 13,1.

${ }^{65}$ A. BALIL, (1980), pp.12-13, nº 14 .

${ }^{66}$ Sobre esta pieza en particular: G. LIPPOLD, (1918), p.88, fig. 4; P. C. BOL, (1983), pp. 141-143, nº 40; B. S. RIDGWAY, (1990), p. 252, lám.127;
} 
apoya en una roca. Variantes en la posición del tronco más o menos inclinado hacia delante o la presencia o ausencia del manto, extremos éstos que dependen mucho del gusto del copista o de sus comitentes. Esta musa es una reelaboración del siglo II o I a. C. de un original cercano al círculo praxitélico ${ }^{67}$, que se reconoce en la Melpómene del Vaticano ${ }^{68}$. A ésta seguirían fielmente un grupo de estatuas, mientras que aquellas que presentan variantes, singularmente en la torsión del tronco, se agrupan en torno a la figura de Francfort, entre las cuales se han de incluir las dos hispánicas ${ }^{69}$.

Existen otros testimonios de la presencia, en escultura, de musas halladas en villae de Hispania, más no entraremos en más detalles por no alargar estas líneas ${ }^{70}$. En cuanto a la perduración iconográfica no tenemos noticias a partir del siglo III, salvo el caso de los sarcófagos, ya comentados, donde su aparición es exponente de la ideología imperante en determinados estratos de la sociedad, generalmente cultos. En esta ideología tienen cabida por una parte las creencias filosóficas de que una vida dedicada al estudio y al culto de las musas conlleva una purificación y su consiguiente heroización y por otra, como consecuencia de la anterior, las ideas de inmortalidad y de triunfo sobre la muerte ${ }^{71}$.

Tan sólo contamos como perduración del tema iconográfico, hasta el Bajo Imperio, con las imágenes de musas que aparecen en los mosaicos, aunque, por supuesto, sin posibilidades de reconocimientos estilísticos ${ }^{72}$. De este tipo de figuraciones contamos con una serie que si bien si no es numerosa, si es importante cualitativamente. Recordemos a este respecto, siguiendo a Parlasca ${ }^{73}$, los ejemplos de Moncada ${ }^{74}$, Italica $^{75}$, Ulia ${ }^{76}$ y Altafulla ${ }^{77}$ en donde aparecen los bustos de las musas en recuadros, a veces con epígrafes, indicando sus nombres. Los mosaicos que las representan de cuerpo entero, con

${ }^{67}$ G. LIPPOLD, (1918), p. 92, nota 5.

${ }^{68}$ G. LIPPOLD, (1936), III, 1, p. 21, nº 499, lám. 4, 5; H. VON STEUBEN en W. HELBIG, (1963), pp. 48- 49, nº60.

${ }^{69}$ Elenco de ambos grupos en D. MUSTILLI, (1939), pp.67-68, $\mathrm{n}^{\circ}$ 9, lám. XLIII.

${ }^{70}$ Sobre otros testimonios de la presencia de musas en villae: P. RODRÍGUEZ OLIVA, (1993), p. 42, notas 224 y 225.

${ }^{71}$ Vid. supra nota 46. Además: H. MARROU, (1937) y P. BOYANCÉ, (1937).

${ }^{72}$ Sobre las figuras de musas en mosaicos y su significación: A. BALIL, (1980), pp.8-10.

${ }^{73}$ K. PARLASCA, (1959), pp.141-143.

${ }^{74}$ K. PARLASCA, (1959), pp.141, no 10; A. BALIL, (1980), pp.5-11, láms. I-V.

${ }^{75} \mathrm{~K}$. PARLASCA, (1959), loc.cit., $\mathrm{n}^{\circ}$ 9; A BLANCO FREIJEIRO, (1978), pp.65-66, láms.61-73.

${ }^{76}$ K. PARLASCA, (1959), loc.cit., $\mathrm{n}^{\circ} 11$; J. $\mathrm{M}^{\mathrm{a}}$ BLÁZQUEZ, (1981), p.56.

${ }^{77}$ De reciente publicación son dos mosaicos parietales realizados en opus vermiculatum con la representación de las musas Euterpe y Mnemosine: F. TARRATS, (1997), pp.434-435, nº.266 y 267. 
alguna afinidad con las figuras de los sarcófagos, son los mosaicos de Augusta Emerita ${ }^{78}$ e Italica $^{79}$ a los que se suma el magnífico ejemplar de Torre de la Palma (Portugal) ${ }^{80}$, y finalmente, las musas con acompañamiento de sabios y filósofos en el mosaico de Arroniz ${ }^{81}$. Todos estos mosaicos tienen una cronología que los sitúa en los siglos III y IV d.C., salvo los de Els Munts, fechados en la segunda mitad del siglo II d.C..

A través del análisis que se ha desarrollado en las líneas precedentes se ha querido demostrar la presencia en la Península Ibérica de tipos iconográficos, escultóricos fundamentalmente, que fueron muy famosos en la sociedad romana y su indudable pervivencia hasta fechas muy avanzadas en la cronología del Imperio. Creo que puede afirmarse la existencia de ciclos escultóricos de musas en villae, preferentemente situadas a lo largo del litoral mediterráneo, ciclos que repiten modelos muy concretos y precisos, los cuales, como el atribuido a Filisco de Rodas gozaron de una gran reputación. Es bien significativo que la musa Melpómene Farnesio, aún con un atributo que no le es propio como la cornucopia, repita con toda fidelidad el tipo estatuario, pudiéndose afirmar lo mismo de Polimnia, incluso en los sarcófagos. La afirmación anterior sobre la existencia de ciclos de musas pienso que puede sostenerse a raíz del hallazgo de tres musas juntas en Churriana, pues no parece viable que hubiese solo tres sino el conjunto completo y puede que, incluso, en ocasiones, estas divinidades estuviesen presididas por Apolo. Si bien es posible que los otros ejemplares fuesen solo estatuas aisladas con una función ornamental, también es posible plantear la hipótesis de que existieran grupos escultóricos, siendo las esculturas que conocemos las que han perdurado. Pienso que es interesante comprobar el hallazgo de dos ejemplares del tipo Melpómene Francfort en el litoral levantino, musas que, con la Urania Loring, están emparentadas con los prototipos de Agnano.

Asunto distinto a tratar es si los propietarios de las lujosas villae, de donde proceden las estatuas, eran conscientes de su significado y de lo que representaban o, simplemente, despojadas de todo contenido cultual eran motivos iconográficos famosos que solo servían como ornamentación de espacios vacíos que era necesario cubrir. El caso de los sarcófagos puede ser distinto por los cambios efectuados en la sociedad hispanorromana y el cambio de ideología que se va produciendo desde fina-

\footnotetext{
${ }^{78}$ K. PARLASKA, (1959), p.142, no 16; A. BLANCO FREIJEIRO, (1978), pp.30 ss., $n^{\circ}$ 9, láms.12-20.

${ }^{79}$ K. PARLASKA, (1959), loc.cit., $\mathrm{n}^{\circ}$ 17; A. BLANCO FREIJEIRO, (1978), p.53, lám. 60; C. CELESTINO, (1977), pp. 361 ss.
}

${ }^{80}$ J. Ma BLÁZQUEZ, (1980), pp. 1215 ss. y, especialmente, 132 ss., figs. 1 y 3.

${ }^{81}$ K. PARLASKA, (1959), loc.cit., $\mathrm{n}^{\circ}$ 25; A. FERNÁNDEZ DE AVILÉS, (1945), 342 ss.; Sobre todos los mosaicos mencionados véase también: J. Mª BLÁZQUEZ, (1993), pp.411-412. 
les del siglo II d. C. y en la siguiente centuria. La proliferación de creencias filosóficas en las que las musas juegan un papel importante orientadas al consuelo ante la llegada de la muerte, justifica en buena manera su proliferación. En todo caso la elección de modelos iconográficos de musas para acompañar a la persona en la vida o en la muerte dependería, como es lógico, de la formación intelectual del comitente, sin que, en la actualidad, con los datos fragmentarios que se poseen pueda adelantarse, sin riesgo de errar, una respuesta.

\section{Bibliografía General}

A. ADRIANI, (1931), BullCom, LIX, pp. 179 y ss.

J. ANDRÉ - R. BLOCH - A. ROUVERT, (1981), Pline l'Ancient. Histoire Naturelle XXXVI, (Ed. Les Belles Lettres), París.

L. BAENA DEL ALCÁZAR, (1984), Catálogo de las esculturas romanas del Museo de Málaga. Málaga.

L. BAENA DEL ALCÁZAR, (1998), «Tipología y funcionalidad de las esculturas femeninas vestidas de Hispania», Actas de la III Reunión sobre Escultura Romana en Hispania, (en prensa).

A. BALIL, (1960), «La Urania Loring». Sobre un tipo helenístico de Musa», Zephyrus, XI, pp. 238 y ss.

A. BALIL, (1975), «La Urania Loring», Jábega, pp. 32-35.

A. BALIL, (1978), «Esculturas romanas de la Península Ibérica», StArch, 51.

A. BALIL, (1983 a), «Esculturas romanas de la Península Ibérica VI», StArch, 73.

A. BALIL, (1983 b), «Esculturas romanas de la Península Ibérica VI», BSAA, XLIX.

A. BALIL, (1986 a), «Esculturas romanas de la Península Ibérica VII y VIII», StArch, 76.

A. BALIL, (1986 b), «Esculturas romanas de la Península Ibérica VII y VIII», BSAA, LII.

A. BALIL, (1988), «Esculturas romanas de la Península Ibérica IX», BSAA, LIX.

G. BATTAGLIA, (1934), «Una statua di musa velata», BullCom, VIII, pp. 7-16.

G. BECATTI, (1951), «Arte e gusto negli scrittori latini», Firenze.

M. BERGES, (1969-1970), «Informe sobre 'Els Munts'», BAT, LXIX-LXX, p. 174.

O. BIE s.v. «Musen» en W. H. ROSCHER, (1984), Ausfürliches Lexikon griechische und römischen Mythologie, II, 2, Leipzig. 
M. BIEBER, (1955), The Sculpture of Hellenistic Age, New York.

A. BLANCO FREIJEIRO, (1957), Catálogo de la Escultura. Museo del Prado, Madrid.

A. BLANCO FREIJEIRO, (1978 a), Mosaicos de Itálica, Madrid.

A. BLANCO FREIJEIRO, (1978 b), Mosaicos de Mérida, Madrid.

J.Mª. BLÁZQUEZ, (1980), «Los Mosaicos romanos de Torre de la Palma (Portugal)», AEspA, 53, pp. 125 y ss.

J.Mª BLÁZQUEZ, (1981), Mosaicos romanos de Córdoba, Jaén y Málaga, Madrid.

J.Ma . BLÁZQUEZ, (1993), Mosaicos romanos de España, Madrid.

P.C. BOL, (1983), Bildwerke aus Stein und aus Stuck von archaischer Zeit bis zur Spätantike. Liebieghaus-Museum Alter Plastik, Band I, Melsungen.

P. BOYANCÉ, (1937), Le culte des Muses chez les phiplosophes grecs, París.

J.C. CASTER, (1984), «The Date of the Altar of Athena at Priene and its Reliefs» en Studi e Materiali, 6. Alessandria e il mondo ellenistico-romano. Studi in onore di Achille Adriani, III, pp. 748-764.

C. CELESTINO, (1977), «Mosaicos perdidos de Italica», Habis, 8, pp. 371 y ss.

F. CUMONT, (1942), Recherches sur le symbolisme funeraire des romains, Paris.

L. FAEDO, (1994 a), s.v. «Mousa, Mousai», en LIMC, VII, 1, pp. 991 y ss.

L. FAEDO, (1994 b), s.v. «Musae» en LIMC, VII, 1, pp. 1030 y ss.

A. FERNÁNDEZ DE AVILÉS, (1945), «El mosaico de las musas de Arroniz y su restauración en el Museo Arqueológico Nacional», AEspA, 18, pp. 342 y ss.

G. FIORELLI, (1884), NotSc, VIII, p. 377.

A. GARCÍA Y BELLIDO, (1949), Esculturas romanas de España y Portugal, Madrid.

L. GUERRINI, (1958), s.v. «Archelaos», en EAA, I, pp. 53 y ss.

R. HORN, (1931), Stehende Weibliche Gewandstatuen in der Hellenistischen Plastik, München.

W. KLEIN, (1921), Von antiken Rokoko, Wien.

G. KLEINER, (1942), Tanagrafiguren, Berlin.

E.M. KOPPEL, (1985), Die römischen Skulpturen von Tarraco, Berlin.

W. KROLL, (1938), s.v. «Philiskos»m en Pauly-Wissowa, XIX, 2, cols. 2978 y ss. 
L. DE LACHENAL en A. GIULIANO, Museo Nazionale Romano, I, Roma, 1979, pp. 118-121.

J. LANCHA, (1994), s.v., «Musae» en LIMC, VII, 1, pp. 1013 y ss.

E. LA ROCCA, (1984), «Philiskos a Roma. Una testa di musa dal tempio di Apollo Sosiano», Studi e Materiali, 6. Alessandria e il modo ellenistico-romano. Studi in onore di Achille Adriani, III, pp. 629 y ss.

L. LAURENZI, (1955-1956), «Sculture inedite del museo de Coo», ASAtene, XVIIXVIII, pp. 59-156.

L. LAURENZI, (1965 a), s.v. «Philiskos» $1^{\circ}$, en EAA, VI, pp. 122 y ss.

L. LAURENZI, (1965 b), s.v. «Rodia, Arte ellenistica», en EAA. VI, pp. 760 y ss.

I. LINFERT- REICH, (1971), Musen und Dichterinnenfiguren des vierten und frühen dritten Jahrhunderts, Köln.

G. LIPPOLD, (1918), «Musengruppen», $R M$, 33, pp. 64 y ss.

G. LIPPOLD, (1950), Griechische Plastik (HdArch), III, 1, pp. 333 y ss.

H. MANDERSCHEID, (1981), «Die Skulpturenausstatung der Kaiserzeitlichen Thermenanlangen», Mon. Artis Romanae, 15, pp. 81-82.

M.T. MARABINI MOEVS, (1981), «Le Muse di Ambracia», BdA, 12, pp. 1-58.

H. MARROU, (1937), Mousikós áner, Grenoble.

G. MENDEL, (1912-1914), Catalogue des sculptures grecques, romaines et byzantines, I-III, Constantinopla (Ed. Anast. Roma, 1966)

P. MORENO, (1994), Scultura ellenistica, I-II, Roma.

D. MUSTILLI, (1939), Il Museo Mussolini, Roma.

J.M. NOGUERA CELDRÁN, (1991), La ciudad romana de Carthago Nova: La Escultura, Murcia.

J.M. NOGUERA CELDRÁN, (1992-1993), «Algunas consideraciones sobre el sarcófago con musas y pensadores del Museo de la Catedral de Murcia», Imafronte, 89, pp. 293 y ss.

J. ONIANS, (1996), Arte y pensamiento en la época helenística, Madrid.

L. PADUANO FAEDO, (1981), «I sarcofagi romani con Muse», ANRW, II, 12, 2, pp. 65 y ss.

B. PANELLA, (1966-1967), «Iconografía delle Muse sui sarcofagi romani». StMisc, 
12,2 , pp. 65 y ss.

K. PARLASCA, (1959), Die römischen Mosaiken in Deutschland, Berlin.

P. PENSABENE, (1989), Il teatro romano di Ferento, Roma.

C. PIETRANGELI, (1949-1951), «La villa tiburtina detta di Cassio», RendPontAcad, 25-26, pp. 157-181.

D. PINKWART, (1965), Das Relief des Archelaos von Priene und die «Musen des Philiskos», Kallmünz.

D. PINKWART, (1967), «Die Musenbasis von Halikarnass», Antike Plastik, VI, pp. 89-94.

J.J. POLLITT, (1989), El arte helenistico, Madrid.

A. QUYREL, (1992), s.v. «Mousa, Mousai» en LIMC, VI, 1, pp. 657 y ss.

B.S. RIDGWAY, (1990), Hellenistic Sculpture, I, Bristol.

M. RODRÍGUEZ DE BERLANGA, (1903), Catálogo del Museo Loringiano, Málaga.

P. RODRÍGUEZ OLIVA, (1993), «Ciclos escultóricos en la casa y en la ciudad de la Bética», Actas de la I Reunión sobre Escultura romana en Hispania, Madrid, pp. 23 y ss.

P. RODRÍGUEZ OLIVA, (1994), «Materiales arqueológicos y epigráficos para el estudio de los cultos domésticos en la España romana», Actas del VIII Congreso Español de estudios Clásicos, III, Madrid.

A. RUESCH, (s.a.), Guida ilustrata del Museo Nazionali di Napoli, Napoli.

M. SCHEDE, (1920), «Zu Philiskos, Archelaos und den Musen», RM, 35, pp. 65 y ss.

J. SIEVEKING, (1917), «Das Relief des Archelaos von Priene», RM, 32, pp. 74 y ss.

V. DE SOUZA, (1990), Corpus Signorum Imperii Romani. Portugal, Coimbra.

H. VON STEUBEN en W. HELBIG, (1963), Führer durch die öffentlichen Sammlungen klassischer Altertumer in Rom, Tübingen.

F. TARRATS, (1997), en Hispania Romana. De tierra de conquista a provincia del Imperio, Madrid.

K.M. TURR, (1971), «Eine Musengruppe hadrianischer Zeit: Die sogennabten Thespiaden», MonArtis Romanae, 10, Berlín.

C. WATZINGER, (1903), Das Reliefs des Archelaos von Priene, Berlín.

M. WEGNER, (1966), Die Musensarkophage. Die antike Sarkophag-Relifs, V, 3, Berlín. 

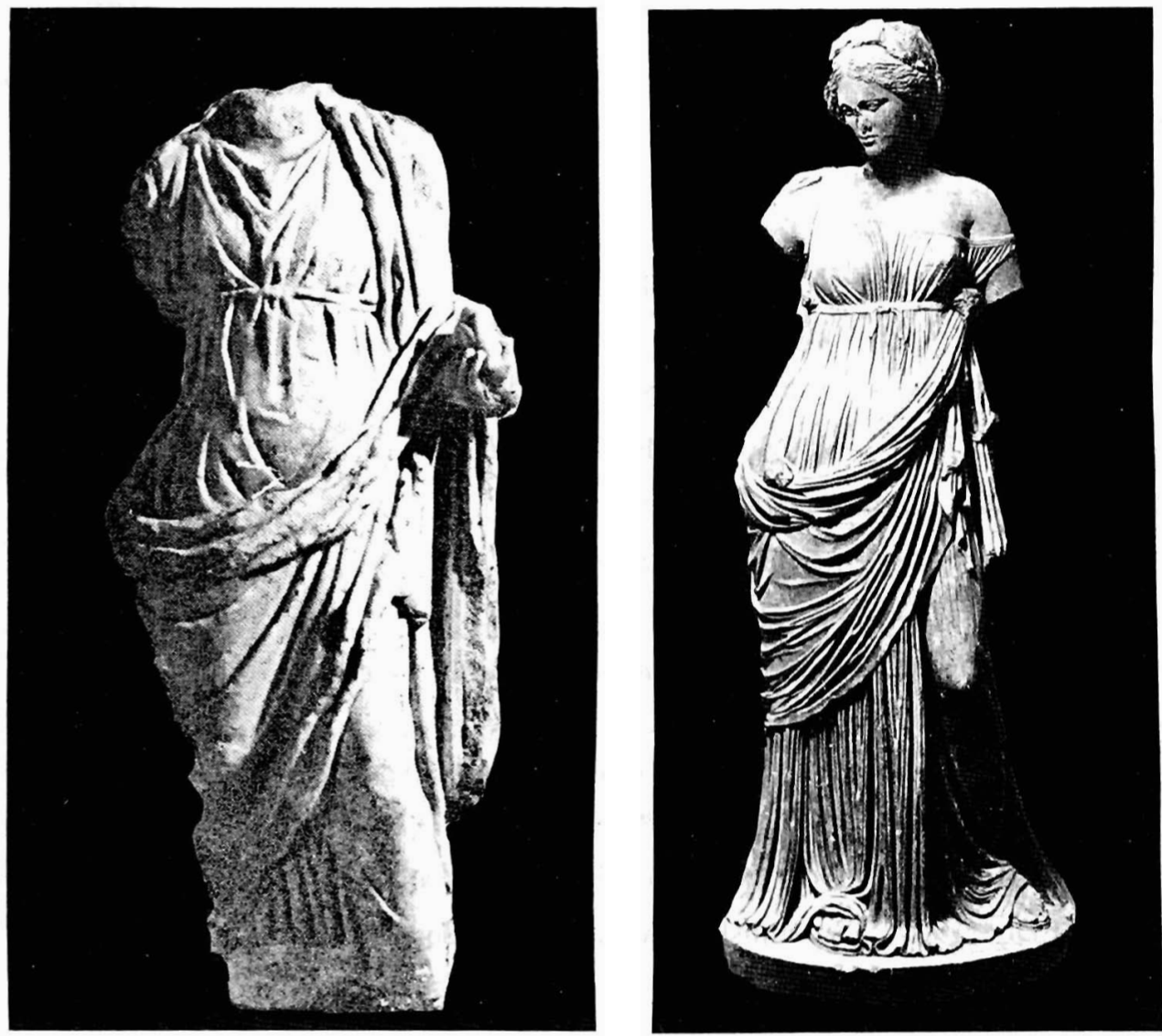

\section{LÁMINA I}

1 Musa Melpómene Farnesio de Els Munts, según A. Balil.

2 Musa Melpómene Farnesio Museo Nazionale Romano. Roma. 

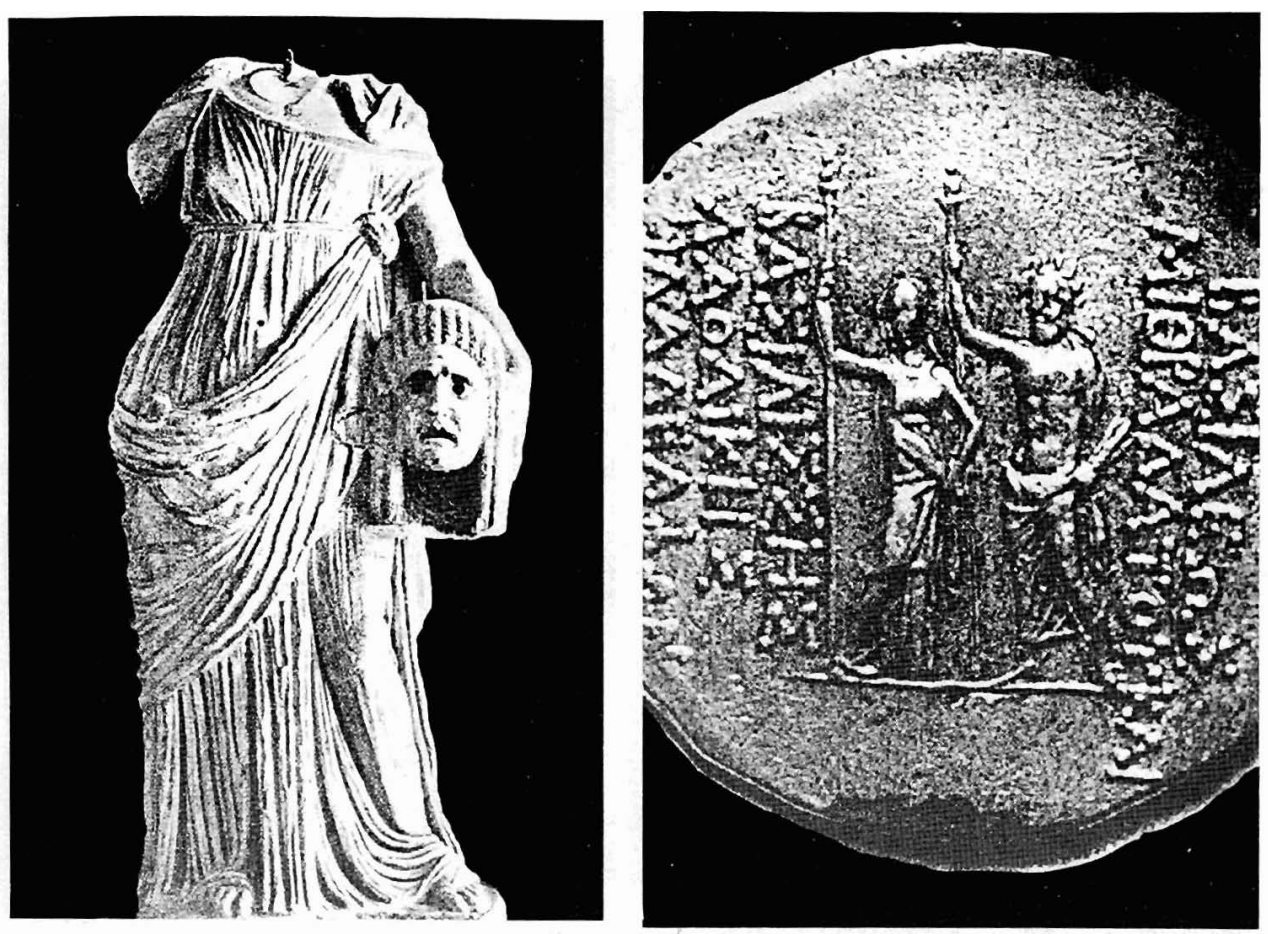

LÁMINA II

1 Musa Melpómene Farnesio. Museo Nazionale. Nápoles. Según Battaglia.

2 Detalle de la tetradracma de Mitrídates IV y Laodicea, según Pinkwart. 

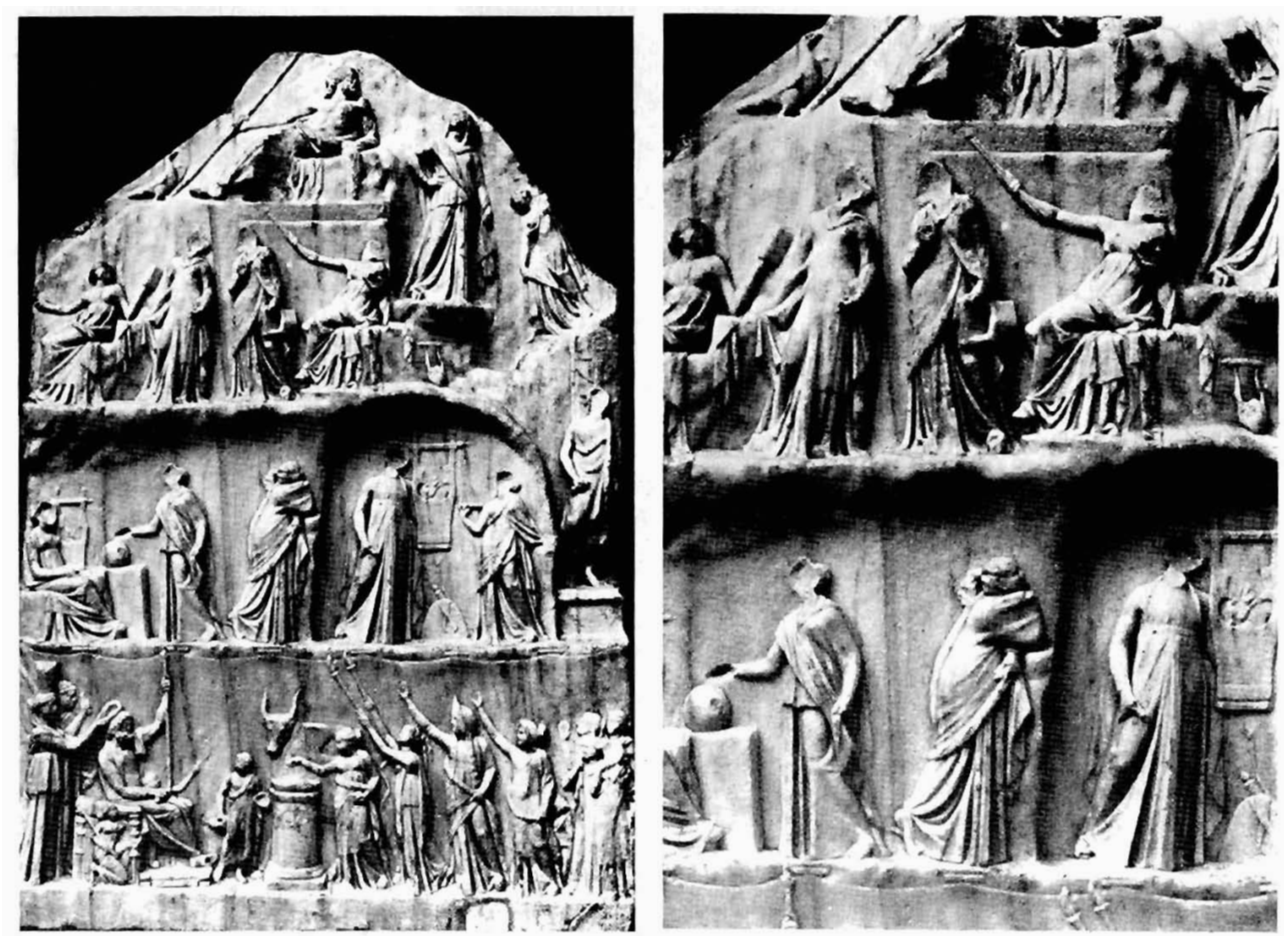

LÁMINA III

1 Relieve de Arquelao de Priene. Museo Británico, según EAA.

2 Relieve de Arquelao de Priene. Detalle de los registros II y II, según EAA. 

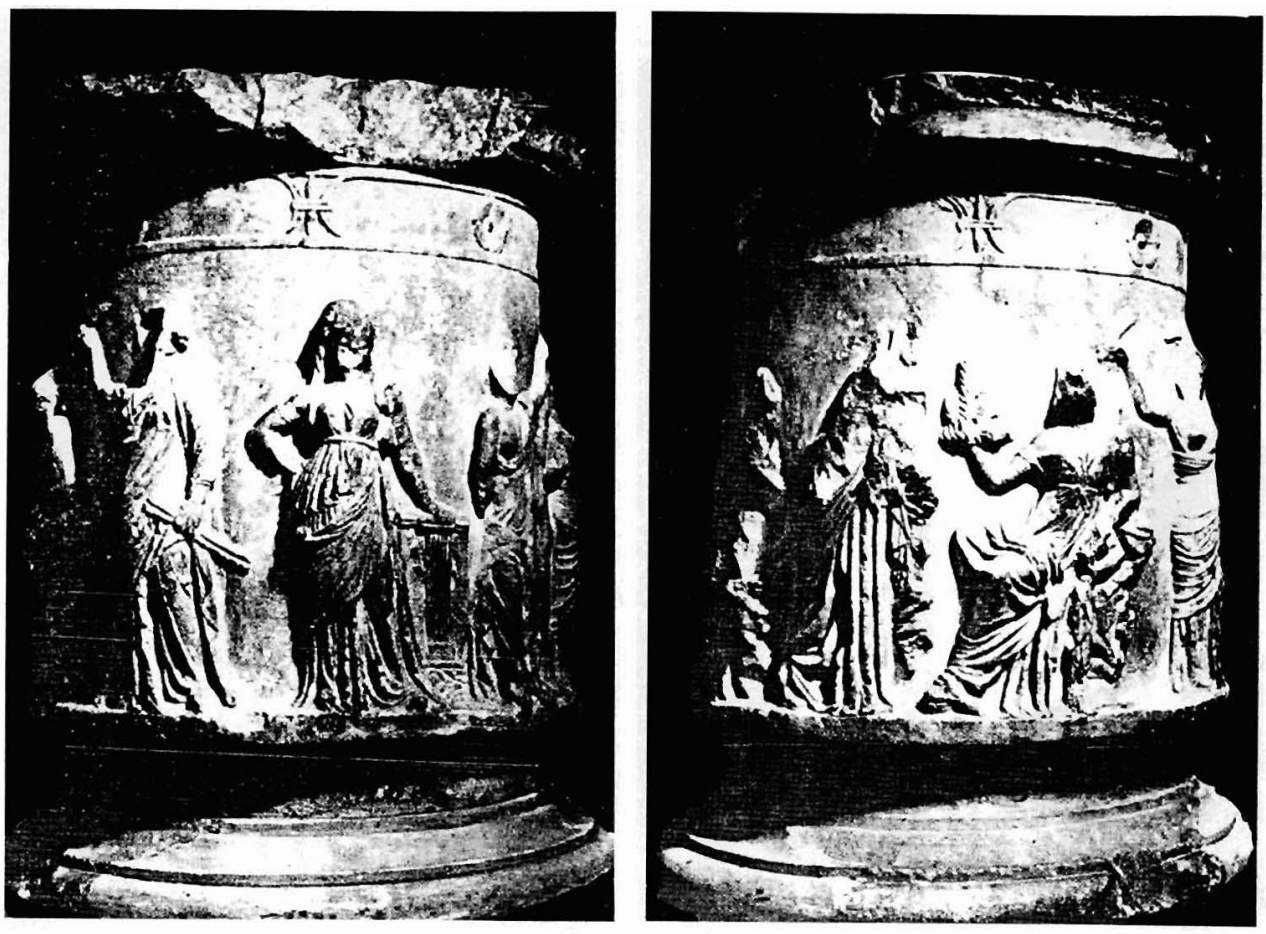

LÁMINA IV

1 Basa de Halicarnaso. Museo Británico. Melpómene. Según Pinkwart.

2 Basa de Halicarnaso. Museo Británico. Polimnia. Según Pinkwart. 

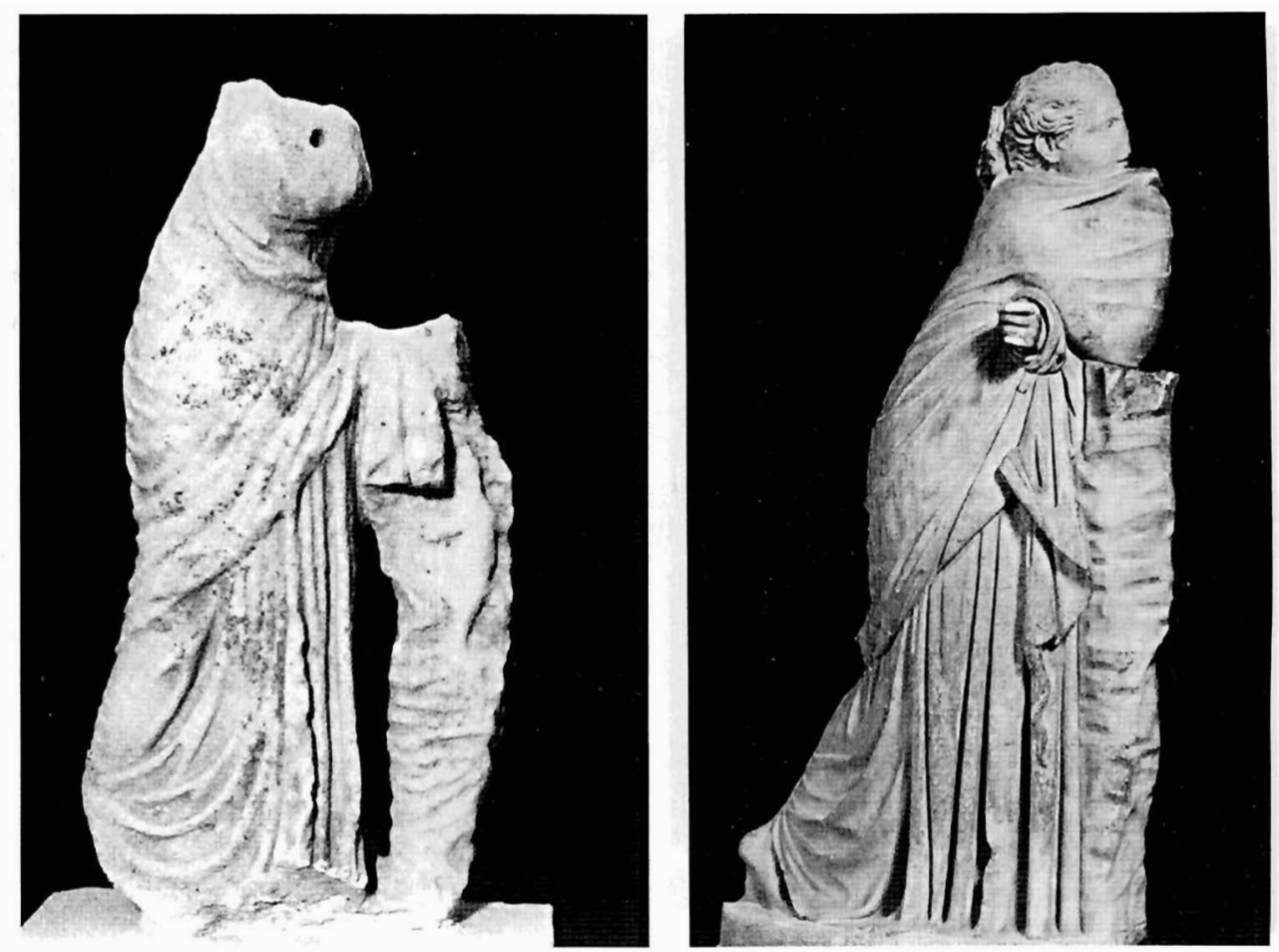

LÁMINA V

1 Musa Polimnia de Cartagena, según Noguera.

2 Musa Polimnia. Museo Nuovo Capitolino, según Moreno. 

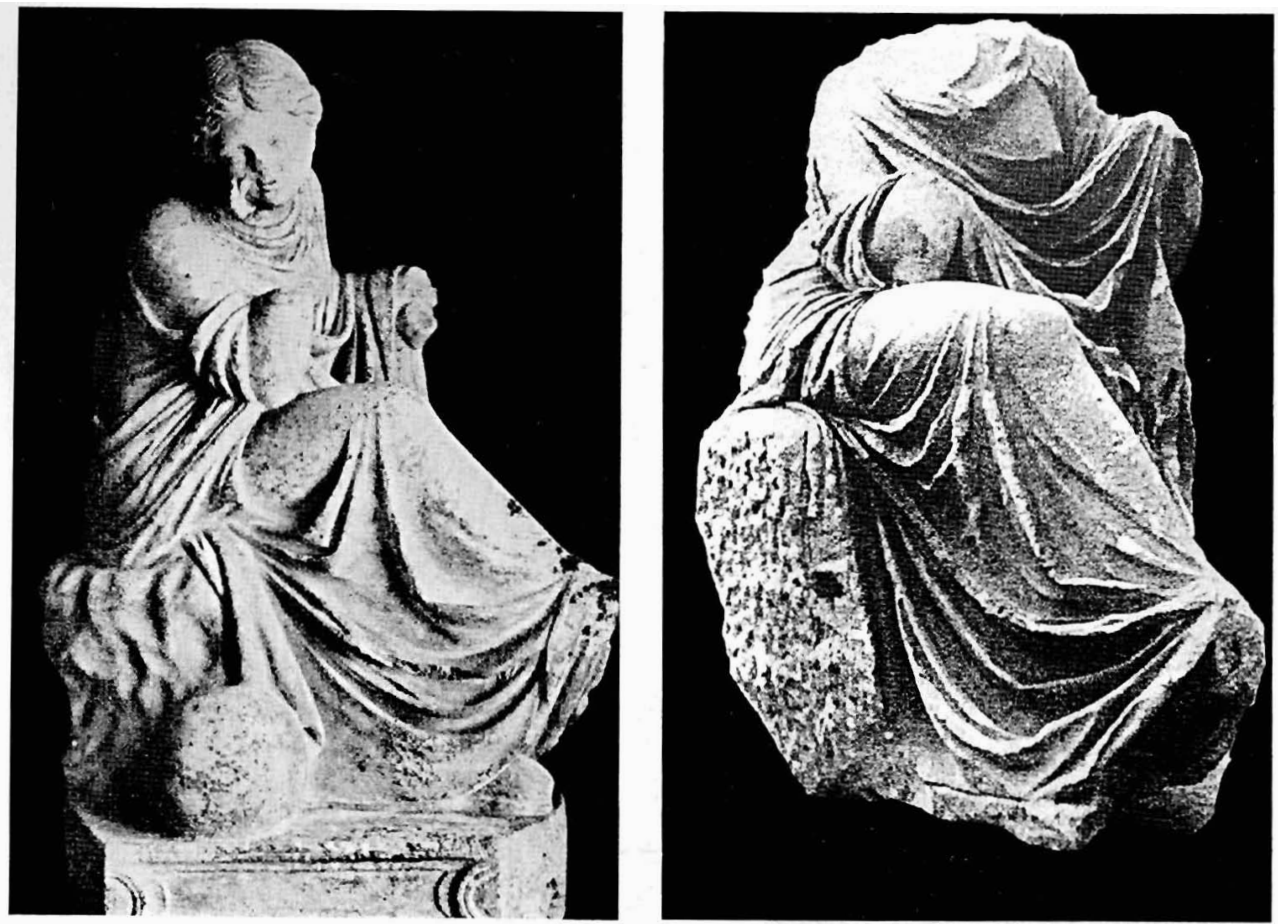

LÁMINA VI

1 Musa Urania Loring-Francfort, según Balil.

2 Musa Urania Afyon Karahisar, según Pinkwart. 

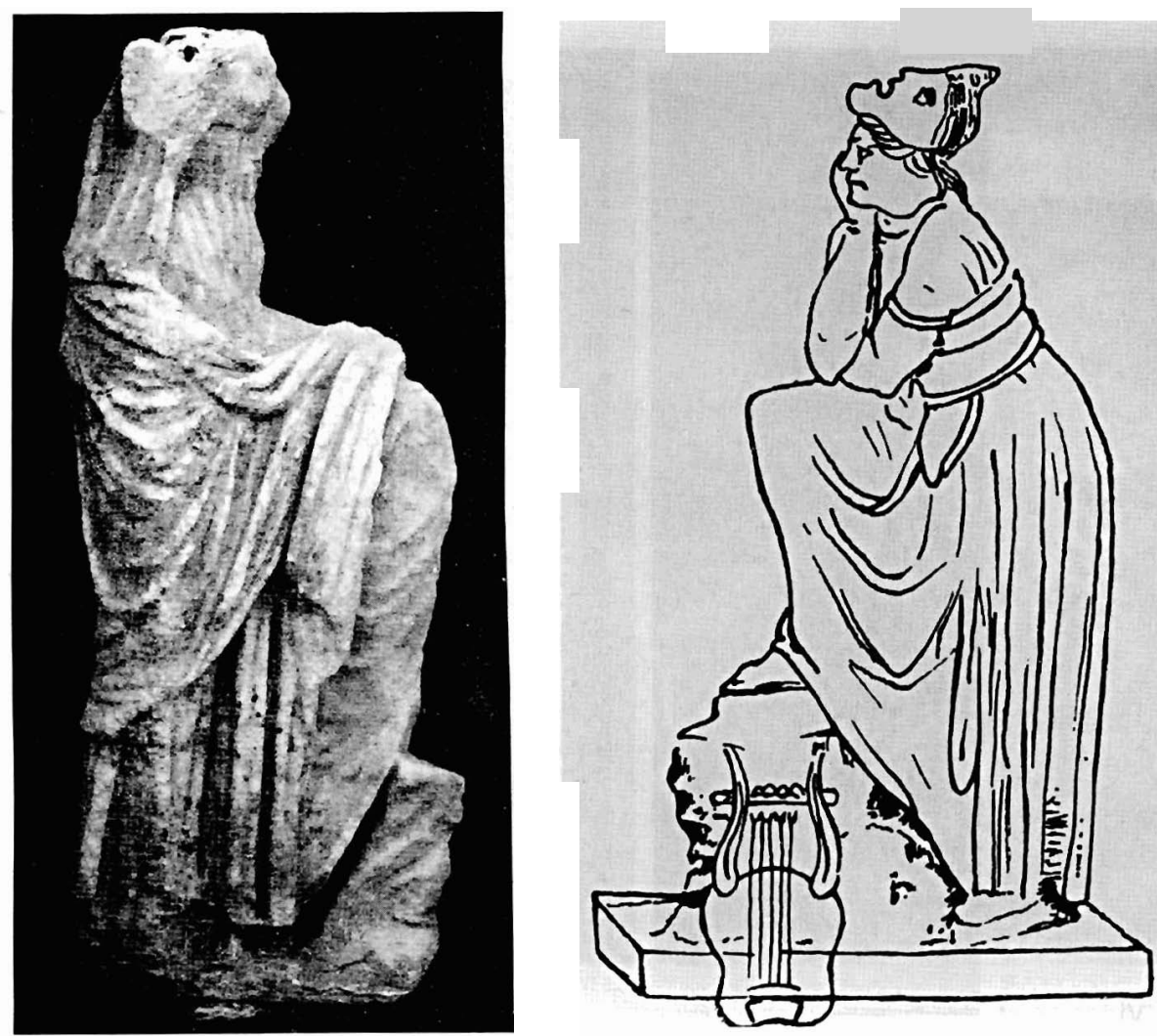

LÁMINA VII

1 Musa Melpómene Francfort de Cartagena, según Balil.

2 Musa Melpómene Francfort de Sagunto, según Balil. 